
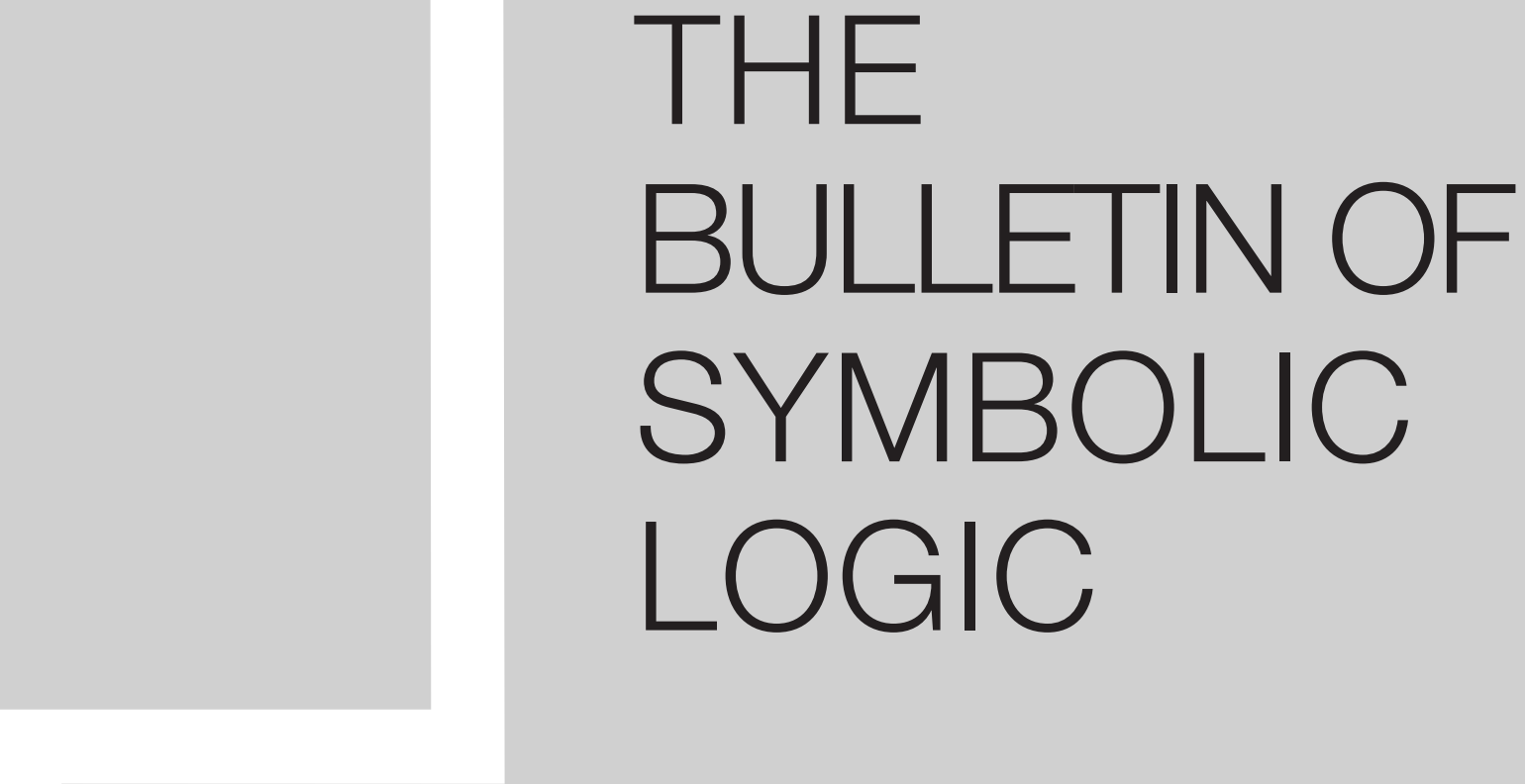

Edited by

Frank Wagner, Managing Editor

Patricia Blanchette Menachem Kojman

Andrea Cantini Leonid Libkin

Thierry Coquand André Nies

Deirdre Haskell

Reviews Editors

Ernest Schimmerling, Managing Editor for Reviews

Mark Colyvan

Colin McLarty

Anuj Dawar

Rahim Moosa

Michael Fourman

Henry Towsner

Steffen Lempp

Kai Wehmeier

Bernard Linsky

VOLUME $21 \cdot 2015$

Copyright $\odot 2015$ by the Association for Symbolic Logic. All rights reserved.

Reproduction by photostat, photo-print, microfilm, or like process by permission only. 


\section{CONTENTS OF VOLUME 21}

ARTICLES

Areces, Carlos and Orbe, Ezequiel. Symmetries in modal logics 373

BARTO, LiBOR. The constraint satisfaction problem and universal algebra

Beeson, Michael, Boutry, Pierre, and Narboux, Julien. Herbrand's theorem and non-Euclidean geometry

Boutry, Pierre. See Beeson, Michael.

Corcoran, John and Masoud, Hassan. Existential-import mathematics .......................... 1

Dyckhoff, Roy, Negri, SARA. Geometrisation of first-order logic ................................... 123

Ebert, Philip A. See Green, J. J.

Foreman, Matthew. Chang's conjecture, generic elementary embeddings and inner models for huge cardinals

Green, J. J., Rossberg, Marcus, and Ebert, Philip A. The convenience of the typesetter; notation and typography in Frege's Grundgesetze der Arithmetik

Kučera, Antonín, Nies, André, and Porter, Christopher P. Demuth's path to randomness

LuPINI, MARTINO. The classification problem for automorphisms of $\mathrm{C}^{*}$-algebras

Mancosu, Paolo and Zach, Richard. Heinrich Behmann's 1921 lecture on the decision problem and the algebra of logic

Masoud, Hassan. See Corcoran, John.

Narboux, Julien. See Beeson, Michael.

Negri, Sara. See Dyckhoff, Roy.

Nies, André. See Kučera, Antonín.

Orbe, Ezequiel. See Areces, Carlos.

Pillay, Anand and Sklinos, Rizos. Saturated free algebras revisited

Porter, Christopher P. See Kučera, Antoní.

Rossberg, Marcus. See Green, J. J.

Sklinos, Rizos. See Pillay, Anand.

Zach, Richard. See Mancosu, Paolo.

\section{REVIEWS}

BEN YAACOV, ITAÏ. Model theory of operator algebras 425

Coskey, SAmuel. Two articles on the classification of separable $\mathrm{C}^{*}$-algebras

Cummings, James. Recent papers on the tree property by Itay Neeman, Dima Sinapova, and Spencer Unger

Hart, Bradd. K. Tent and M. Ziegler, A Course in Model Theory

Hirst, JefFry L. D. R. Hirschfeldt, Slicing the truth: On the computable and reverse mathematics of combinatorial principles

Sinapova, Dima. I. Neeman, Forcing with sequences of models of two types. Notre Dame Journal of Formal Logic

In Memoriam

In Memoriam: Grigori E. Mints, 1939-2014

\section{OBITUARY}

VÄÄNÄNEN, Jouko. Jaakko Hintikka 1929-2015.

Meetings of the Association for Symbolic Logic

2014 European Summer Meeting of the Association for Symbolic Logic, Logic Colloquium '14, Vienna, Austria, July 14-19, 2014.

2014 Spring Meeting of the Association for Symbolic Logic, Westin Gaslamp Quarter, San Diego, California, April 16-17, 2014 
2014 North American Annual Meeting of the Association for Symbolic Logic, University of Colorado, Boulder, Boulder, CO, USA, May 19-22, 2014.

2014 Winter Meeting of the Association for Symbolic Logic, Marriott Philadelphia Downtown, Philadelphia, Pennsylvania, December 28-30, 2014

2015 North American Annual Meeting of the Association for Symbolic Logic, University of Illinois at Urbana-Champaign, Urbana, IL, USA, March 25-28, 2015.

2014-2015 Winter Meeting of the Association for Symbolic Logic, Henry B. Gonzalez Convention Center, San Antonio, TX, USA, January 12-13, 2015

Meetings Sponsored by the Association for Symbolic Logic

21st Workshop on Logic, Language, Information and Computation (WoLLIC 2014), Valparaiso, Chile, September 1-4, 2014

Model Theory and Groups, Istanbul 4, Istanbul, Turkey, March 26-28, 2015.

VII Conference and II School on Topology, Algebra, and Categories in Logic (TACL), 2015, Fisciano (School) and Ischia (Conference), Italy, June 15-19, 2015 (School) and June 21-26, 2015 (Conference)

Notices . $104,244,366,496$

Officers and Committees of the Association for Symbolic Logic 446

Members of the Association 451 
THE BULLETIN OF SYMBOLIC LOGIC (ISSN print: 1079-8986, ISSN online: 1943-5894) is published quarterly, in the months of March, June, September. and December, by the Association for Symbolic Logic, Inc., 124 Raymond Avenue, Poughkeepsie, NY 12604-0001, USA. Periodicals postage is paid at Poughkeepsie NY and at additional mailing offices. The BULLETIN is distributed with THE JOURNAL OF SYMBOLIC LOGIC. The 2015 annual subscription price for the two journals, in either print or electronic form, is US\$764, $£ 479$ or $€ 589$; the print/electronic bundle prices are $\$ 850, £ 534$ or $€ 657$ : visit http:// journals . cambridge.org/bs 1 for more information. Postmaster: Send address changes to Journals Customer Services Department, Cambridge University Press, 32 Avenue of the Americas, New York, NY 10013, USA. Business correspondence should be sent to the Secretary-Treasurer of the Association, Charles Steinhorn (address below).

Subscription orders for the JOURNAL and BULLETIN, or REVIEW should be sent to subscr i pt ions newyork@cambridge.org. All orders must be accompanied by payment by check, credit card (Visa, MasterCard, JCB or American Express only), or debit card. To receive a replacement copy of the BULLETIN, please report damaged, defective or missing issues within nine months of the date of publication.

Volumes 1 through 19 of the BULLETIN are available online at JSTOR: volumes 1 through 20 via Cambridge University Press, $\mathrm{ht} \mathrm{tp}: / /$ journal s cambridge.org/bs 1 - access to the latter is free to members.

Individual membership in the Association is open to anyone interested in its work. Annual dues for members are US\$94, $£ 59$ sterling or $€ 72$ ( $\$ 47, £ 30$ sterling or $€ 36$ for student, emeritus and unemployed members; see http://wwwaslonline.org/membership-individual.html for more information, including conditions and privileges). Dues include subscriptions to the current volumes of the JOURNAL, the BULLETIN, and the REVIEW.

Institutional membership in the Association is available to any academic institution or department. Annual institutional membership dues for 2015 are US\$1075 (full) or $\$ 625$ (basic); privileges include choices of current subscriptions, back volumes, regular individual and student memberships.

Requests for information, applications for new membership, renewals of institutional membership, business correspondence, and notices or announcements for publication in the BULLETIN should be sent to Charles Steinhorn, Secretary-Treasurer of the ASL, Box 742, Vassar College, 124 Raymond Avenue, Poughkeepsie, NY 12604, USA. The electronic mail address of the Association's business office is as1@vassar.edu. Requests for back issues should be sent to Cambridge University Press, address above.

Individual membership renewals, notices of change of address, and dues payments, should be sent to Association for Symbolic Logic, c/o Journals Customer Services Department, Cambridge University Press, 32 Avenue of the Americas, New York, NY 10013, USA, USmemberservices@cambridge.org.

The paper used in the BULLETIN is acid-free and falls within the guidelines established to ensure permanence and stability.

The BULLETIN has been registered with the Copyright Clearance Center, Inc. The appearance of a code at the bottom of the first page of an article indicates the copyright owner's consent for copying beyond that permitted by Sections 107 or 108 of the US Copyright Law, provided that the per-copy fee stated in the code is paid directly to Copyright Clearance Center Inc., 222 Rosewood Drive, Danvers, MA 01923, USA. This consent does not extend to copying for general distribution, for advertising or promotion purposes, for creating new collective works, or for resale. Specific written permission for such copying must be obtained from the Association. 
Cambridge Journals Online For further information about this journal please go to the journal web site at: journals.cambridge.org/bsl 